\title{
Imobilização com muleta de Thomas de fratura de rádio-ulnar em bezerro: relato de caso
}

Gilson Antônio Pessoa", Daniel Fantinel Rodrigues, Jerbeson Hoffmann da Silva, Vanessa de Lima, Milana Paese, Elisa Nappi

Biasin, Guilherme Novello, Patrícia Roberta Weber, Suélen Letícia dos Santos

Universidade de Caxias do Sul (UCS), Caxias do Sul, RS, Brasil

*Autor correspondente

e-mail: gilsonpessoavet@yahoo.com.br

\section{Resumo}

As fraturas de ossos longos ocorrem com relativa frequência em animais de grande porte, porém, devido aos custos e à dificuldade da realização deste tipo de tratamento, normalmente estes animais são submetidos à eutanásia. A tentativa de resolução de fraturas em animais de grande porte deve levar em consideração o valor econômico do animal, mérito genético, localização e tipo de fratura, custo do tratamento e o prognóstico do caso em questão. Nos últimos anos, várias técnicas têm sido desenvolvidas ou adaptadas para esta finalidade, mas ainda não existem dispositivos de fixação desenvolvidos especificamente para esses animais. Para a estabilização de fraturas nestes indivíduos, podem ser utilizados parafusos e pinos intramedulares, placas ortopédicas, haste intramedular, fixação externa, fixação com gesso e muleta de Thomas modificada. Esta última opção, associada ou não com o uso de gesso, apresenta melhores resultados em comparação com os métodos de fixação interna. Foi atendido no Hospital Veterinário da Universidade de Caxias do Sul, uma fêmea bovina Zebuína, com 6 meses de idade, 180kg, com fratura localizada no membro torácico direito. Com a realização do exame radiográfico, constatou-se que o animal apresentava uma fratura do tipo fechada, diafisária, oblíqua, simples e completa do rádio, e uma fratura fechada, diafisária, transversa simples e completa de ulna. Devido à dificuldade da realização dos métodos de fixação e estabilização tradicionais, optou-se pela realização da tala de Thomas modificada. Para tal, o animal foi sedado por meio da aplicação de $0,1 \mathrm{mg} / \mathrm{kg}$ de cloridrato de xilazina e posicionado em decúbito lateral esquerdo. Primeiramente, foi realizado o reposicionamento dos ossos fraturados. Para a confecção da muleta de Thomas modificada, utilizou-se ataduras, malhas ortopédicas, uma haste metálica para confecção do suporte e gesso. Para alívio da dor, foram utilizados flunixin meglumine e tramadol. 0 animal não se adaptou à primeira tentativa, demonstrado bastante desconforto. Diante do caso, a tala foi removida e efetuou-se a confecção da tala de Thomas; desta vez, não se aderiu ao método modificado. Nesta segunda 
tentativa, o animal demonstrou um nível de adaptação satisfatório, apresentando melhora clínica nos dias subsequentes. Conclui-se que a utilização da tala de Thomas, modificada ou não, bem como métodos simples de estabilização, utilizando materiais como malhas ortopédicas, ataduras, gesso, hastes metálicas ou até mesmo canos de PVC, constituem um método prático, efetivo e de baixo custo, principalmente para a imobilização de fraturas distais em animais de grande porte. 